\title{
Leukocyte populations and cytokine expression in the mammary gland in a mouse model of Streptococcus agalactiae mastitis
}

\begin{abstract}
Correspondence
Delfina Tavares

dtavares@icbas.up.pt
\end{abstract}

Received 22 October 2008

Accepted 6 March 2009

\author{
Gabriela Trigo, ${ }^{1,2}$ Márcia Dinis, ${ }^{1,2}$ Ângela França, ${ }^{1}$ Elva Bonifácio Andrade, ${ }^{1,2}$ \\ Rui M. Gil da Costa, ${ }^{1}$ Paula Ferreira ${ }^{1,2}$ and Delfina Tavares ${ }^{1,2}$ \\ ${ }^{1}$ Instituto de Ciências Biomédicas de Abel Salazar (ICBAS), Universidade do Porto, Porto, Portugal \\ ${ }^{2}$ Instituto de Biologia Molecular e Celular (IBMC), Universidade do Porto, Porto, Portugal
}

\begin{abstract}
Streptococcus agalactiae is a contagious, mastitis-causing pathogen that is highly adapted to survive in the bovine mammary gland. This study used a BALB/c mouse model of Streptococcus agalactiae mastitis to evaluate leukocyte populations in regional lymph nodes and cytokine expression in the mammary gland involved in the immune response against Streptococcus agalactiae. It was found that the bacteria replicated efficiently in the mammary gland, peaking after $24 \mathrm{~h}$ and increasing by 100 -fold. Dissemination of bacteria to systemic organs was observed $6 \mathrm{~h}$ after infection. At the same time, a massive infiltration of polymorphonuclear cells and an increase in the inflammatory cytokines interleukin (IL)- $1 \beta$, IL- 6 and tumour necrosis factor- $\alpha$ were detected in mammary glands, indicating an early inflammatory response. A decrease in the levels of inflammatory cytokines in mammary glands was observed $72 \mathrm{~h}$ after infection, accompanied by an increase in the levels of IL-12 and IL-10, which were related to a gradual decrease in bacterial load. An increase in the number of macrophages and B220 ${ }^{+}$lymphocytes and similar increases in both $\mathrm{CD} 4^{+}$and $\mathrm{CD} 8^{+} \mathrm{T}$ cells in regional lymph nodes were observed, being most pronounced 5 days after infection. Moreover, increased levels of anti-Streptococcus agalactiae antibodies in the mammary gland were observed 10 days after infection. Overall, these data suggest that the host exhibits both innate and acquired immune responses in response to Streptococcus agalactiae mastitis.
\end{abstract}

\section{INTRODUCTION}

Streptococcus agalactiae is a well-known major contagious pathogen that causes subclinical bovine mastitis (Keefe et al., 1997; Merl et al., 2003; Wilson \& Richards, 1980) and has a substantial impact on the quantity and quality of milk produced. This pathogen is a parasite of the bovine mammary gland and can spread widely within a herd during the milking process (Keefe, 1997). As well as the financial implications of bovine mastitis, the extensive use of antibiotics in the treatment and control of mastitis has implications for human health through an increased risk of antibiotic-resistant bacterial strains and the presence of antibiotics in milk intended for human consumption (Berry \& Hillerton, 2002). One of the most practical means for dealing with mastitis in the dairy industry is to enhance the natural host defence mechanisms (Kotwal, 1997). However, the roles of the various immune system components in mammary gland defence against infection

Abbreviations: H\&E, haematoxylin and eosin; IFN- $\gamma$, gamma interferon; IL, interleukin; MHC, major histocompatibility complex; PE, phycoerythrin; $\mathrm{PMN}$, polymorphonuclear cell; TNF- $\alpha$, tumour necrosis factor- $\alpha$. are not well understood (Kotwal, 1997). Both cytokine production and leukocyte populations play important roles during bacterial infection; however, the relative contributions of these factors to the pathogenesis of mastitis have not yet been fully determined.

Mouse models are increasingly used to study the mechanisms of pathogenesis, immune responses and the control of mastitis induced by different pathogens, mainly using Staphylococcus aureus and Escherichia coli as model pathogens (Brouillette \& Malouin, 2005; Notebaert \& Meyer, 2006). Only a few murine studies have studied Streptococcus agalactiae as a mastitis pathogen (Notebaert \& Meyer, 2006). Although differences may exist between ruminant and murine mammary glands (Notebaert \& Meyer, 2006), the mouse model of mastitis offers a useful alternative for evaluating the immunology and pathology of mastitis and provides an economical model for vaccine development.

Here, we evaluated the microbial load and histopathological alterations in mammary tissue, as well as the specific antibodies against Streptococcus agalactiae produced in the mammary gland and serum following infection. In 
addition, because the establishment of infection is governed, in part, by the nature of the host immune response to the invading organism, we also evaluated the local cytokine production and the lymphoid cells recruited to the mammary gland during Streptococcus agalactiae mastitis. The results of this study help to delineate the roles of the various leukocyte populations in mouse mammary gland defence against infection by Streptococcus agalactiae.

\section{METHODS}

Bacteria. Streptococcus agalactiae strain BA64 was isolated from a cow with mastitis (a kind gift of Dr Niza Ribeiro, SEGALAB-Laboratório de Sanidade Animal e Segurança Alimentar SA, Porto, Portugal); stocks of the bacteria were stored at $-70{ }^{\circ} \mathrm{C}$ in Todd-Hewitt broth (Difco) with $25 \%(\mathrm{v} / \mathrm{v})$ glycerol. To prepare the inoculum, overnight cultures of Streptococcus agalactiae were diluted 1:10 in Todd-Hewitt broth and incubated for another $4 \mathrm{~h}$ to reach the exponential growth phase. The bacteria were then washed three times and suspended in cold endotoxin-free PBS (Sigma). Based on a standard curve generated by plotting c.f.u. as a function of $\mathrm{OD}_{600}$, the cultures were further diluted in PBS to the desired number of c.f.u. $\mathrm{ml}^{-1}$.

Mice. Female BALB/c mice (6-8 weeks old) were purchased from Charles River Laboratories. Animals were housed in the animal facilities of the Institute Abel Salazar (Porto, Portugal) during the experiments. The animal experiments were performed according to the European Convention for the Protection of Vertebrate Animals used for Experimental and Other Scientific Purposes (ETS 123) and 86/609/EEC Directive and Portuguese rules (DL 129/92).

Preparation of whole-cell lysates from Streptococcus agalactiae. Whole-cell lysates of Streptococcus agalactiae were prepared by disrupting the bacterial cells by sonication (10 cycles of $30 \mathrm{~s}$ at $100 \mathrm{~W}$ ) on ice using a Branson cell disrupter (model W $185 \mathrm{D}$ ), centrifugation at $29000 \mathrm{~g}$ for $30 \mathrm{~min}$ and filtration through a $0.22 \mu \mathrm{m}$ Millipore filter. Full disruption of Streptococcus agalactiae cells was confirmed by light microscopy. Protein concentration was determined by using the Lowry method, and the lysates were stored at $-70{ }^{\circ} \mathrm{C}$ until use.

Streptococcus agalactiae mastitis. BALB/c mice were infected with Streptococcus agalactiae by intramammary injection on the 10th15 th day of lactation, as described by Chandler (1970). Various doses of Streptococcus agalactiae were evaluated, but only a dose of $10^{8}$ c.f.u. was able to establish an intramammary infection lasting 15 days that allowed study of the different leukocyte populations involved in the infectious process. Briefly, groups of six lactating mice were removed from their pups $1-2 \mathrm{~h}$ before bacterial inoculation of the mammary glands. The mice were anaesthetized with ketamine $\left(100 \mathrm{mg} \mathrm{kg}^{-1}\right.$; Imalgéne, Meriel) and xylazine (10 $\mathrm{mg} \mathrm{kg}^{-1}$; Rompun, Bayer). Using a binocular microscope, the left and right fourth mammary glands (L4 and R4, respectively) were injected with $100 \mu \mathrm{l}$ of a suspension containing $10^{8}$ c.f.u. Streptococcus agalactiae through the teat canal using a 33-gauge blunt needle. The mothers were returned to the pups $2 \mathrm{~h}$ after the injections. At 6, 12, 24, 72, 120, 240 and $360 \mathrm{~h}$ after infection, six lactating mice were euthanized to evaluate bacterial growth. Mammary glands, kidneys, spleen and liver were removed aseptically, weighed and homogenized in $1 \mathrm{ml}$ endotoxin-free PBS (Sigma) for mammary glands, kidneys and spleen, and in $3 \mathrm{ml}$ for liver. For each animal, the kidneys were pooled. The infected L4s were used for c.f.u. counts and the infected R4s were used for histological analyses (see below). The number of c.f.u. was determined by plating logarithmic dilutions of the tissue samples on Todd-Hewitt agar medium (Difco). After $24 \mathrm{~h}$ of incubation at $37^{\circ} \mathrm{C}$, the number of c.f.u. was evaluated.

Histopathological analysis. The mammary glands used for histological examination were fixed in $10 \%$ buffered formaldehyde at room temperature for $24 \mathrm{~h}$ and embedded in paraffin wax. Sections ( $4 \mu \mathrm{m}$ thick) were stained with haematoxylin and eosin (H\&E) or were Gram stained. Sections were examined by light microscopy and pictures were obtained using a DSC-L1 Nikon Imaging System.

Evaluation of antibodies in mammary glands and serum. For antibody and cytokine evaluation (see below), the mammary glands were homogenized as described above and centrifuged at $13000 \mathrm{~g}$ for $10 \mathrm{~min}$ at $4{ }^{\circ} \mathrm{C}$. The fat was removed and the supernatant was collected and stored at $-20{ }^{\circ} \mathrm{C}$ until analysis. Mice sera were collected by retro-orbital bleeding. The sera and mammary glands of infected and control mice were evaluated for Streptococcus agalactiae-specific antibodies by ELISA. Briefly, polystyrene microtitre plates (Nunc) were coated with Streptococcus agalactiae whole-cell lysate $(10 \mu \mathrm{g}$ $\mathrm{ml}^{-1}$ ) and incubated overnight at $4{ }^{\circ} \mathrm{C}$. The wells were then saturated with $1 \%(\mathrm{w} / \mathrm{v})$ BSA in PBS for $1 \mathrm{~h}$ at room temperature. Serial dilutions of samples were plated and incubated for $2 \mathrm{~h}$ at room temperature. After washing, bound antibodies were detected by adding alkaline phosphatase-coupled monoclonal goat anti-mouse IgG isotypes (IgG1, IgG2a, IgG2b and IgG3) and IgA (Southern Biotechnology Associates) for $1 \mathrm{~h}$ at room temperature. After washing, substrate solution containing p-nitrophenyl phosphate (Sigma) was added; the reaction was stopped by adding $0.1 \mathrm{M}$ EDTA ( $\mathrm{pH}$ 8.0). The $A_{405}$ was measured. ELISA antibody titres were expressed as the reciprocal of the highest dilution giving an absorbance of 0.1 above that of the control (no sample added) (Tavares et al., 1995).

Detection of cytokines in mammary glands. The levels of the cytokines interleukin (IL)-1 $\beta$, IL-6, IL-10, IL-12, tumour necrosis factor (TNF) $-\alpha$ and gamma interferon (IFN- $\gamma$ ) in the mammary glands of Streptococcus agalactiae-infected and control mice were quantified by using a Quantikine M Murine ELISA kit (R\&D Systems), according to the manufacturer's instructions.

Flow cytometry. For cytometric analysis, mammary lymph nodes from Streptococcus agalactiae-infected and control mice were collected at different times after infection, homogenized and resuspended in balanced salt solution supplemented with $10 \mathrm{mM}$ sodium azide and $1 \%(\mathrm{w} / \mathrm{v})$ BSA. The following monoclonal antibodies were used: rat anti-mouse CD4 phycoerythrin (PE)-Cy5 conjugate (BD PharMingen); rat anti-mouse CD8 FITC conjugate (BD PharMingen); rat anti-mouse B220 FITC conjugate (BD PharMingen); rat anti-mouse CD69 PE conjugate (BD PharMingen); rat anti-mouse Mac1 FITC conjugate (BD PharMingen); and major histocompatibility complex (MHC) class II biotin conjugate (Southern Biotechnology Associates) revealed with PEconjugated streptavidin (BD PharMingen). Dead cells were excluded according to propidium iodide incorporation. Immunofluorescent cytometric analysis was performed using a FACScan (Becton Dickinson) with CellQuest software (Becton Dickinson).

Statistical analysis. Data were analysed by single-factor analysis of variance using Microsoft Excel 2003.

\section{RESULTS}

\section{Bacterial growth in infected mammary glands}

As shown in Fig. 1, growth of Streptococcus agalactiae in the mammary glands peaked at $24 \mathrm{~h}$ post-infection (p.i.) 


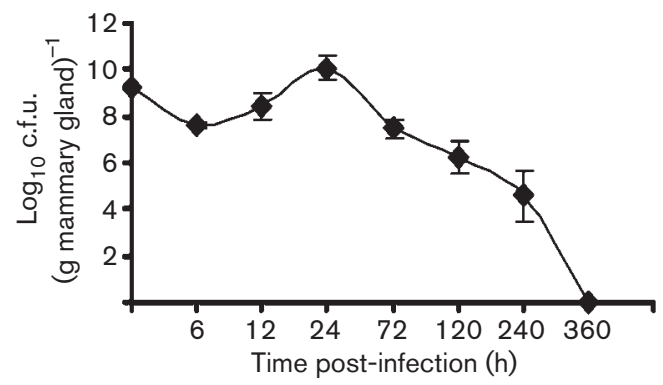

Fig. 1. Time course of the number of Streptococcus agalactiae c.f.u. recovered from the mammary glands of female BALB/c mice infected with $10^{8}$ c.f.u. per mammary gland. Results are reported as the mean c.f.u. \pm SD of six mice per time point. The figure shows the results of one representative experiment of two independent experiments.

[mean $2.1 \times 10^{10}$ c.f.u. $(\mathrm{g} \text { tissue })^{-1}$ ]. Thus the exponential phase of colonization occurred within the first $24 \mathrm{~h}$ of infection. No animals died during the experiment (data not shown). After $24 \mathrm{~h}$, a sharp decrease in bacterial load occurred, followed by a more gradual decrease from 72 to $240 \mathrm{~h}$ and another sharp decline after $240 \mathrm{~h}$. Therefore, clearance of bacteria began at $24 \mathrm{~h}$ after infection (Fig. 1). Dissemination of bacteria from the mammary glands to the kidneys, spleen and liver was observed $6 \mathrm{~h}$ after infection, with a peak in bacterial load occurring after $12 \mathrm{~h}$ for kidneys $\left(6.8 \times 10^{4}\right.$ c.f.u. $\left.\mathrm{g}^{-1}\right)$ and spleen $\left(4.7 \times 10^{5}\right.$ c.f.u. $\left.\mathrm{g}^{-1}\right)$ and after $24 \mathrm{~h}$ for the liver $\left(4.9 \times 10^{3}\right.$ c.f.u. $\left.\mathrm{g}^{-1}\right)$. The bacterial load in these organs remained significantly lower than that in the mammary glands throughout the study. No bacterial colonization was observed in control mice (data not shown).

\section{Histopathological changes in the mammary gland after intramammary infection with Streptococcus agalactiae}

Changes in mammary tissue were evaluated by microscopy following $\mathrm{H} \& \mathrm{E}$ staining. Bacteria in mammary tissue were detected by Gram staining. Microscopic examination showed large bacterial colonies associated with necrosis and moderate polymorphonuclear cell (PMN) infiltration at $6 \mathrm{~h}$ p.i. with Streptococcus agalactiae (Fig. 2b). At $24 \mathrm{~h}$ p.i., an acute inflammatory process was noted. Large areas of necrosis predominantly surrounding the main mammary duct and associated with PMN infiltration were observed (Fig. 2c). Gram staining revealed large numbers of bacteria associated with or phagocytosed by PMNs (Fig. $2 \mathrm{~d}$ ), as well as associated with or internalized by mammary epithelial cells (Fig. 2e). At 3 days p.i., there was a moderate, diffuse, mixed inflammatory infiltration throughout the parenchyma (Fig. 2f), composed of PMNs and mononuclear cells (lymphocytes and macrophages); the situation was similar at 5 days p.i. (Fig. 2 g). At 10 days p.i., there was an increased number of macrophages and lymphoplasmacytic cells, a reduced number of PMNs and mild interstitial fibrosis (Fig. 2h). Finally, at 15 days p.i., the remaining multifocal necrotic areas still associated with purulent infiltration were surrounded by band-like mononuclear infiltrates composed of macrophages and a few lymphocytes (pyogranulomas). Peripheral areas showed extensive mammary glandular atrophy and replacement of mammary parenchyma with fibrous tissue (Fig. 2i). There were no histopathological alterations in the mammary tissue of control mice (Fig. 2a).

\section{Intramammary infection with Streptococcus agalactiae induces local and systemic production of bacterium-specific antibodies}

Anti-Streptococcus agalactiae antibody production was quantified by ELISA at 10 and 15 days post Streptococcus agalactiae infection. The levels of IgG1, IgG2a, IgG2b and IgG3 antibodies in the mammary glands and serum and that of $\operatorname{IgA}$ in the mammary glands were evaluated in infected and control mice. As shown in Fig. 3(a), 10 days after infection, there was a significant increase in the levels of IgA antibodies specific for Streptococcus agalactiae in the mammary glands of infected mice. In addition, there were significant increases in the levels of IgG1, IgG2a, IgG2b and IgG3 antibodies specific for Streptococcus agalactiae at 10 and 15 days p.i. As shown in Fig. 3(b), at 10 and 15 days p.i., there were significant increases in the levels of IgG1, IgG2a, IgG2b and IgG3 antibodies specific for Streptococcus agalactiae in the serum of infected mice. These increases in Streptococcus agalactiae-specific antibodies coincided with the sharp decline in bacterial counts between 120 and $360 \mathrm{~h}$ p.i., possibly indicating a role for specific immunity in control of the disease.

\section{Intramammary infection with Streptococcus agalactiae induces production of pro- and anti- inflammatory cytokines in the mammary gland}

As shown in Fig. 4, the presence of Streptococcus agalactiae induced the production of TNF- $\alpha$ in the mammary gland at $6 \mathrm{~h}$ p.i.; TNF- $\alpha$ levels decreased to control levels by $120 \mathrm{~h}$ p.i. An increase in IL-1 $\beta$ production was evident at $6 \mathrm{~h}$ post-challenge and persisted for $24 \mathrm{~h}$. Increased levels of IL-12 and IL- 6 were detectable within $6 \mathrm{~h}$ of infection. Peak levels of IL-12 were observed at $72 \mathrm{~h}$, whereas IL-6 levels remained constant for $24 \mathrm{~h}$ after infection and decreased by $72 \mathrm{~h}$. Increased levels of IL-10, an antiinflammatory cytokine, were first observed $6 \mathrm{~h}$ after infection, peaked at $72 \mathrm{~h}$ and returned to baseline levels by $120 \mathrm{~h}$ (Fig. 4). No IFN- $\gamma$ was detected in the infected animals at any point after infection (data not shown).

\section{Intramammary infection with Streptococcus agalactiae elicits an increase in leukocyte subpopulations in the mammary lymph nodes}

To investigate the lymphocyte subpopulations involved in Streptococcus agalactiae infection, mammary lymph node 


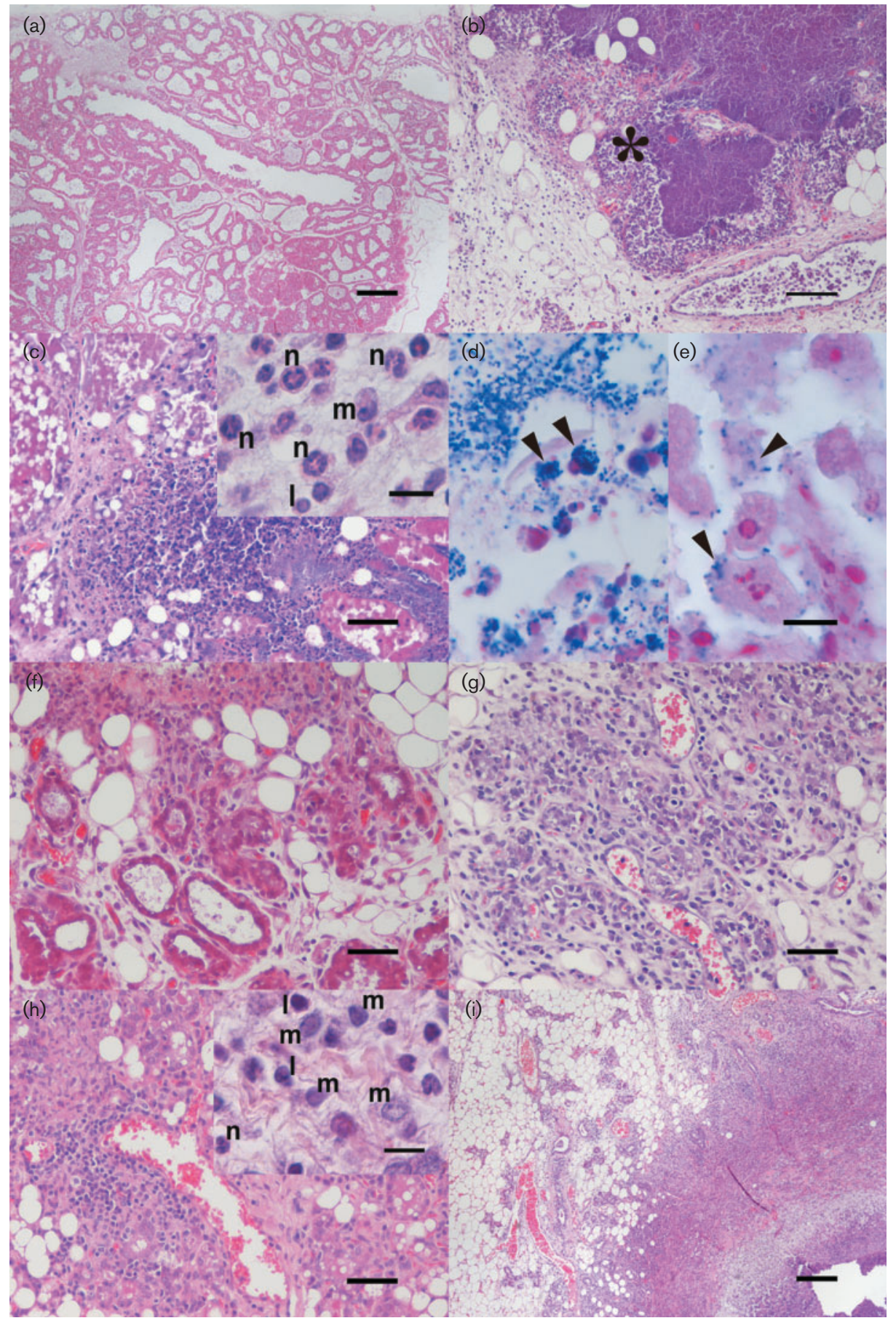

Fig. 2. Microscopic alterations in the mammary glands of female BALB/c mice infected with $10^{8}$ c.f.u. Streptococcus agalactiae per mammary gland. (a) Control: normal mammary tissue. H\&E stained. Bar, $200 \mu \mathrm{m}$. (b) At 6 h p.i.: note the large bacterial colony (star) and PMN infiltration. H\&E stained. Bar, $100 \mu \mathrm{m}$. (c) At 24 h p.i.: mammary necrosis with multiple bacterial colonies. H\&E stained. Bar, $50 \mu \mathrm{m}$. Insert: neutrophils (n) largely predominate over macrophages (m) and lymphocytes (I). H\&E stained. Bar, $10 \mu \mathrm{m}$. (d) At 24 h p.i.: blue-staining cocci free or inside PMNs. Gram stained. Bar, $10 \mu \mathrm{m}$. (e) At 24 h p.i.: bluestaining cocci free or inside epithelial cells. Gram stained. Bar, $10 \mu \mathrm{m}$. (f) At 3 days p.i.: mixed inflammatory infiltrate surrounding glandular structures. H\&E stained. Bar, $50 \mu \mathrm{m}$. (g) At 5 days p.i.: intense interstitial inflammatory cell infiltration. H\&E stained. Bar, $50 \mu \mathrm{m}$. (h) At 10 days p.i.: mild to moderate interstitial fibrosis and intense inflammatory cell infiltration. H\&E stained. Bar, $50 \mu \mathrm{m}$. Insert: macrophages $(\mathrm{m})$ and lymphocytes (I) largely predominate over neutrophils (n). H\&E stained. Bar, $10 \mu \mathrm{m}$. (i) At 15 days p.i.: large pyogranuloma with central necrosis and neutrophil accumulation surrounded by a band of mononuclear cells. Note replacement of the mammary tissue by adipocytes and fibrous tissue at the periphery. H\&E stained. Bar, $200 \mu \mathrm{m}$. 

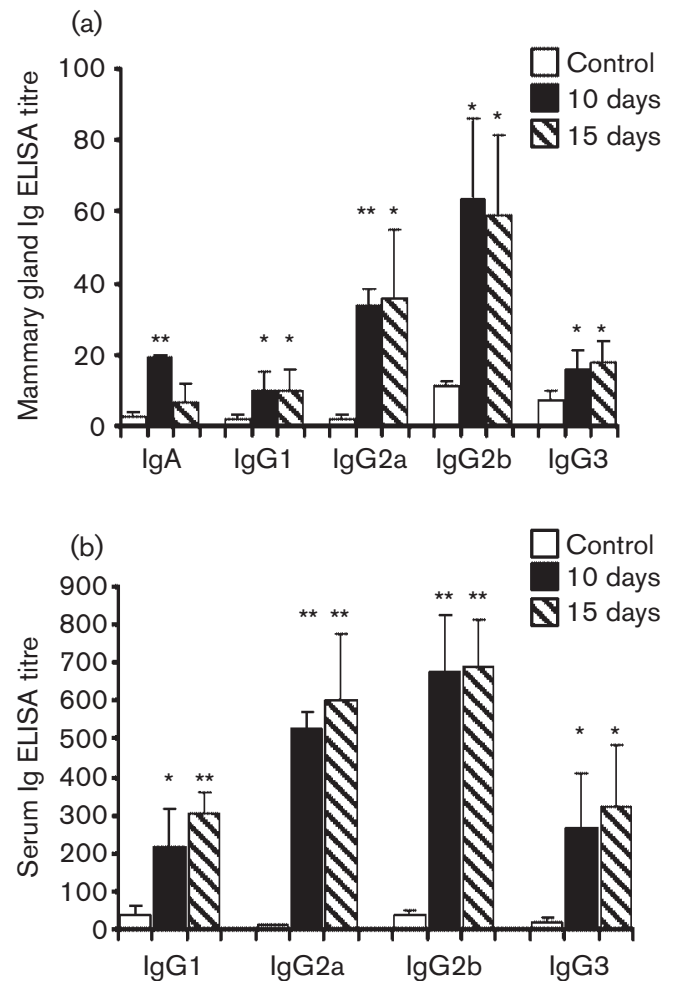

Fig. 3. Comparison of ELISA titres of Streptococcus agalactiaespecific antibodies of the indicated isotypes in mammary glands (a) and serum (b) in control mice and mice infected with $10^{8}$ c.f.u. Streptococcus agalactiae per mammary gland at 10 and 15 days p.i. The results are reported as the mean titre \pm SD for six mice per group. The figure shows the results of one representative experiment of two independent experiments. * $P<0.05$; ${ }^{*}, P<0.001$. cells were collected from infected and control mice and evaluated by flow cytometry. As shown in Fig. 5, an increase in the number of $\mathrm{CD}^{+} 9^{+} \mathrm{B}$ lymphocytes and $\mathrm{CD}^{+}$and $\mathrm{CD}^{+} \mathrm{T}$ cells was observed 1 day after infection. In addition, the percentages of $\mathrm{CD} 69^{+} \mathrm{B}$ lymphocytes and $\mathrm{CD}^{+}$and $\mathrm{CD} 8^{+} \mathrm{T}$ cells were also markedly increased, indicating that these cell populations were activated after Streptococcus agalactiae infection. As shown in Fig. 6, 5 days after infection, there was a more pronounced increase in the total number of $\mathrm{CD}^{+}{ }^{+} \mathrm{T}$ cells, $\mathrm{CD}^{+}{ }^{+} \mathrm{T}$ cells, B cells and $\mathrm{Macl}^{+}$cells in the mammary lymph nodes of infected mice, indicating that activation of these cells was followed by cellular proliferation. At this time, we also observed a significant increase in the expression of MHC II in $\mathrm{Macl}^{+}$cells in mice with mastitis compared with control animals.

\section{DISCUSSION}

Streptococcus agalactiae is a major contagious pathogen that causes subclinical mastitis. There have been reports of a humoral immune response against structural antigens of Streptococcus agalactiae and clinical changes during experimental Streptococcus agalactiae-induced bovine mastitis (Logan et al., 1984, 1986; Mackie \& Logan, 1986), and a few murine studies have used Streptococcus agalactiae as a mastitis-causing pathogen (Chandler, 1970). Nonetheless, little is known about the pathogenesis, immune response and control of mastitis induced by this bacterium. Therefore, to understand the host defence process in Streptococcus agalactiae mastitis, we established a mouse model for mastitis induced by Streptococcus agalactiae. In the present study, we demonstrated consistent local and
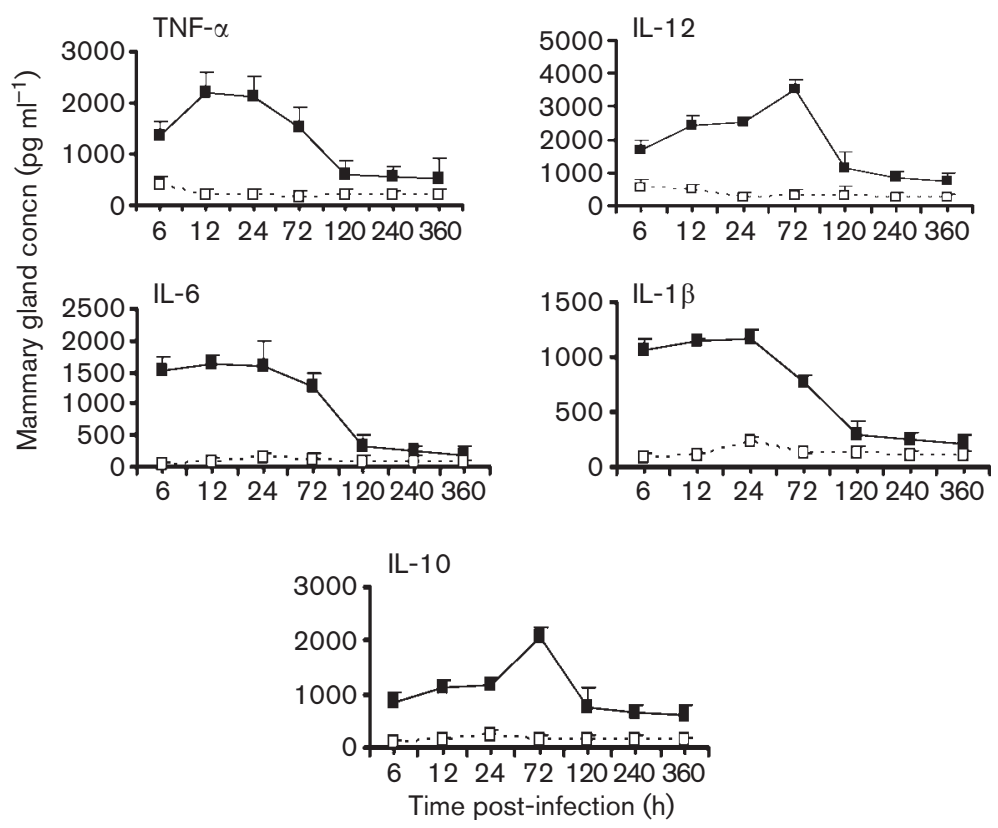

Fig. 4. Levels of cytokines in the mammary glands of female BALB/c mice infected with $10^{8}$ c.f.u. Streptococcus agalactiae per mammary gland at different times after infection. $\mathbf{\square}$, Infected; $\square$, control. The results are expressed as means $\pm S D$ of six mice per group. The figure shows the results of one representative experiment of two independent experiments. 
(a)

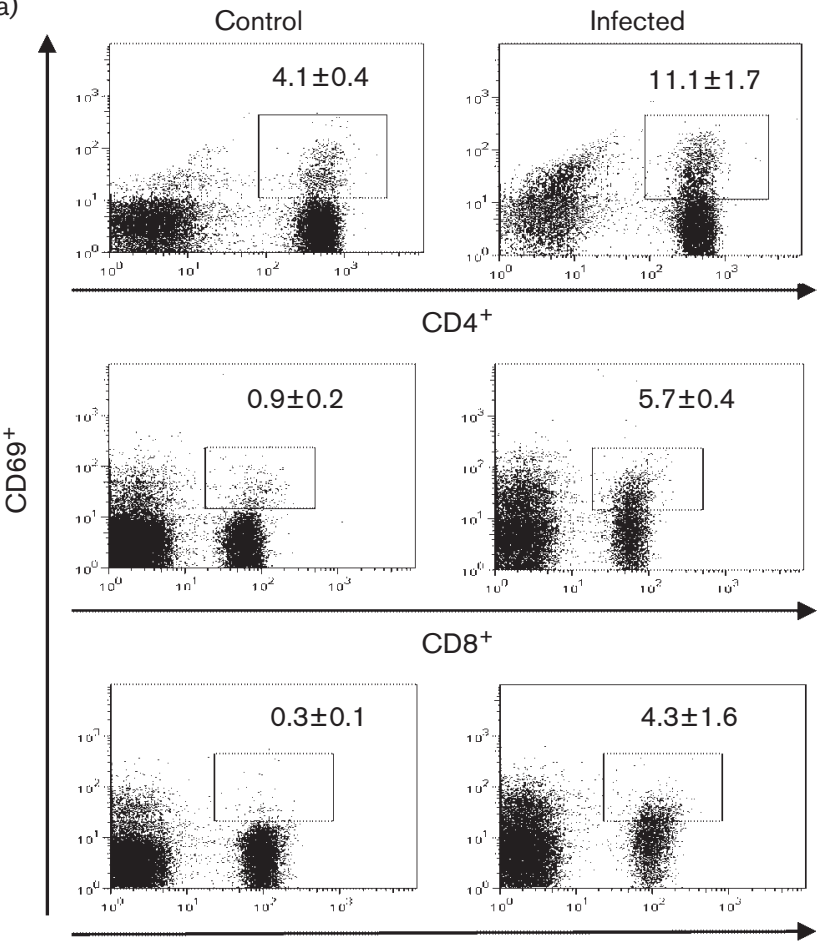

$\mathrm{B} 220^{+}$

(b)

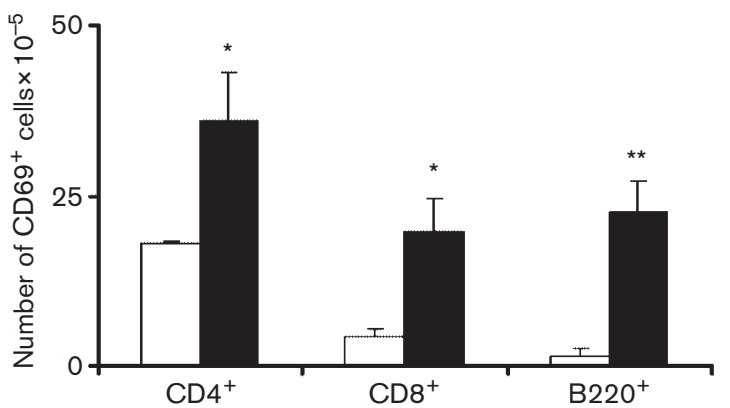

Fig. 5. Flow cytometric analysis of the expression of the early activation marker CD69 on mammary lymph node cells of female BALB/c mice $24 \mathrm{~h}$ after intramammary infection with $10^{8}$ c.f.u. Streptococcus agalactiae per mammary gland. (a) Typical dot plots showing CD69 expression on the surface of $\mathrm{CD} 4^{+}$ and $\mathrm{CD}^{+} \mathrm{T}$ cells and B $\left(\mathrm{B} 220^{+}\right)$lymphocytes in mammary lymph node cells. The numbers inside the plots represent the mean percentage \pm SD of CD69-expressing cells on each gated population $\left(\mathrm{CD} 4^{+}, \mathrm{CD}^{+}\right.$or $\mathrm{B}^{2} 20^{+}$). (b) Numbers of CD69-expressing $\mathrm{B}$ $\left(\mathrm{B}^{2} 20^{+}\right)$and $\mathrm{T}\left(\mathrm{CD}^{+}\right.$and $\left.\mathrm{CD} 8^{+}\right)$cells in control ( $\square$ ) and infected ( $\square$ ) mice. The results are expressed as means \pm SD of six mice per group. The figure shows the results of one representative experiment of two independent experiments. ${ }^{*}, P<0.05 ;{ }^{*}, P<0.001$.
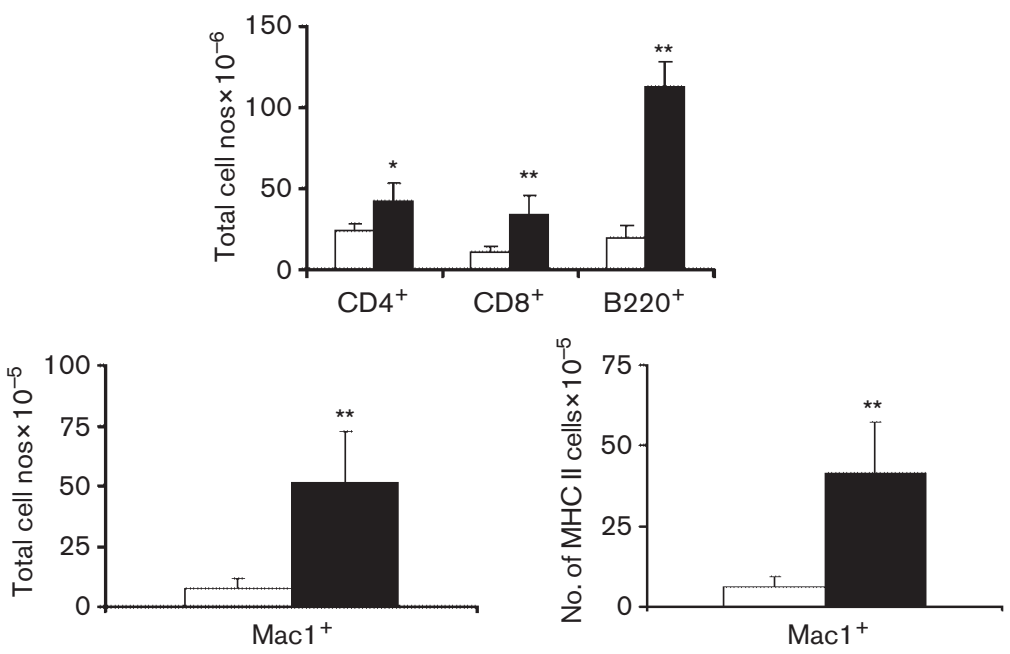

Fig. 6. Flow cytometric analysis of the numbers of $\mathrm{CD}^{+}{ }^{+}$and $\mathrm{CD} 8^{+} \mathrm{T}$ cells, B $\left(\mathrm{B220}^{+}\right)$ cells and $\mathrm{Mac}^{+}{ }^{+}$cells in mammary lymph node cells of control ( $\square$ ) and Streptococcus agalactiae-infected ( $\boldsymbol{\square}$ ) female BALB/c mice $120 \mathrm{~h}$ after infection with $10^{8}$ c.f.u. per mammary gland. The results are expressed as means $\pm S D$ of six mice per group. The figure shows the results of one representative experiment of two independent experiments. ${ }^{*}, P<0.05 ;{ }^{* *}, P<0.001$. 
systemic infection by recovering the bacteria from several organs of Streptococcus agalactiae (strain BA64)-infected mice. To our knowledge, there are no references concerning the systemic dissemination of Streptococcus agalactiae from mammary glands in a mouse model. However, there are studies reporting such dissemination during Staphylococcus aureus mastitis (Brouillette et al., 2004). Within $24 \mathrm{~h}$ of infection, Streptococcus agalactiae had multiplied and spread throughout the mammary tissue, as shown by recovery of bacteria and histological analysis of the mammary glands. These results suggested a lag phase in the ability of Streptococcus agalactiae to adapt and grow in the mammary gland. Additionally, we observed the presence of the bacterium in the mammary epithelial cells. This result may be relevant for the bovine udder, where adherence allows the bacteria to resist removal by fluid flow during milking, whilst internalization allows bacteria to overcome defence mechanisms at mucosal membranes in the first stage of infection (Almeida et al., 2007). It has been shown that Streptococcus agalactiae can adhere to and be internalized into host cells (Rubens et al., 1992), which could explain why antimicrobial treatment is often ineffective and why subclinical infections with Streptococcus agalactiae tend to become chronic.

As reported previously (Bannerman et al., 2004; Shuster et al., 1993), the innate immune response predominates during the early stages of infection and is regulated by proinflammatory cytokines that promote neutrophil recruitment to the infected mammary gland. When macrophages recognize bacteria, they release pro-inflammatory cytokines such as TNF- $\alpha$ and IL-1 $\beta$, which have been shown to be critical for effectively combating primary infection (Bannerman et al., 2004). One recent study showed that IL-1 $\beta$-deficient mice were more severely affected by $E$. coli infection compared with their wild-type littermates (Hertting et al., 2003). However, cytokine production during Streptococcus agalactiae mastitis has not been documented before. In the present study, we observed neutrophil infiltration as early as $6 \mathrm{~h}$ after infection with Streptococcus agalactiae, which was accompanied by an early and marked increase in the levels of the proinflammatory cytokines TNF- $\alpha$, IL- 6 and IL- $1 \beta$ produced by the resident macrophages in mammary glands. Nevertheless, the growth of Streptococcus agalactiae was uncontrolled until $24 \mathrm{~h}$ p.i. As in Staphylococcus aureus mastitis (Yamanaka et al., 2000), IL-1 $\beta$ was increased only in the first $72 \mathrm{~h}$ after infection with Streptococcus agalactiae; after this time, IL- $1 \beta$ levels declined to baseline values. Previous studies in sows and cows have shown that TNF- $\alpha$ is a rapid responder during coliform mastitis (Nakajima et al., 1997; Zhu et al., 2004). Indeed, our findings demonstrated that the mammary gland was a source of TNF- $\alpha$ during Streptococcus agalactiae mastitis. These results contrast with those of a study in which TNF- $\alpha$ and IL-1 $\beta$ were not detected in the milk of cows infected with Streptococcus uberis until $66 \mathrm{~h}$ after challenge (Rambeaud et al., 2003). Here, we found that production of IL-12 was still increased at $72 \mathrm{~h}$ after Streptococcus agalactiae infection, when the levels of other proinflammatory cytokines declined. IL-12 is also required for neutrophil recruitment and is a mediator between innate and acquired immunity (Hornef et al., 2002). We found that the peak in IL-10 correlated with the decrease in TNF- $\alpha$, consistent with reports that IL-10 inhibits TNF- $\alpha$ production (Armstrong et al., 1996; Cassatella et al., 1993). We also observed that increased levels of IL-12 and IL-10 coincided temporally, as has been reported for bovine coliform mastitis (Bannerman et al., 2004), although reports from studies using other model organisms and/or in vitro systems indicated that IL-10 downregulates the expression of IL-12 (Bannerman et al., 2004). In our model, we did not observe an increase in IFN- $\gamma$ in Streptococcus agalactiae-infected mammary glands. However, this could have been due to the elevated levels of IL-10 in the mammary gland; IL-10 is known to downregulate the expression of IFN- $\gamma$. The resolution of the inflammatory process is mediated by upregulation of IL-10, which downregulates pro-inflammatory cytokine production (Spits \& de Waal Malefyt, 1992).

Upregulation of the early activation markers CD69 on B lymphocytes and CD4 and CD8 on T lymphocytes was observed $24 \mathrm{~h}$ after infection. The increase in T-cell numbers in mammary glands infected with Streptococcus agalactiae appeared to be due to similar increases in both $\mathrm{CD}^{+}{ }^{+}$and $\mathrm{CD} 8{ }^{+} \mathrm{T}$-cell numbers, as reported for bovine streptococcal mastitis (Soltys \& Quinn, 1999).

One mechanism used by the immune system to increase phagocytosis and the killing of infectious micro-organisms is the production of specific antibodies at sufficient levels at the site of infection (Leitner et al., 2000). Several isotypes, namely IgG1 and IgG2, can act as opsonins to enhance phagocytosis by neutrophils and macrophages. In contrast, IgA does not aid bacterial opsonization but instead blocks the adherence of micro-organisms and their toxins to epithelial cells, thereby preventing the spread of bacterial disease in the mammary gland. Our results showed that intramammary infection with Streptococcus agalactiae elicited both local and systemic antibody responses. We showed that the antibody response was due mainly to high levels of Streptococcus agalactiae-specific IgA and IgG2 antibodies in mammary glands and high levels of Streptococcus agalactiae-specific IgG2 antibodies in the serum. This antibody production coincided with the development of a chronic process and was associated with a reduction in the number of bacteria in the mammary gland. This result suggests that the acquired immune response also plays a role in the control of Streptococcus agalactiae-induced mastitis.

To our knowledge, this is the first comprehensive report of a mouse model of Streptococcus agalactiae mastitis characterized by the induction of pro-inflammatory cytokines in the mammary gland and histological alterations similar to those observed in cows with Streptococcus 
agalactiae mastitis (Maxie, 2007). Indeed, the inflammatory process was quite similar to that described for bovine Streptococcus agalactiae mastitis, with an exuberant exudative phase followed by granulation tissue proliferation, fibrosis and mammary atrophy (Maxie, 2007). Infected mice also showed extensive, multifocal mammary necrosis that resulted in multifocal pyogranulomas, which has not been described in naturally infected cattle. This could be because the high number of bacteria used for inoculation allowed deeper invasion and the consequent formation of pyogranulomas.

In conclusion, this study provides important information about the cellular and humoral immune responses in the mouse model of Streptococcus agalactiae mastitis.

\section{ACKNOWLEDGEMENTS}

This work was supported by the Fundação da Ciência e Tecnologia (FCT) grant POCI/CVT/57144/2004 and FEDER. The authors gratefully express their acknowledgement of Célia Lopes for technical assistance in the histopathological procedures.

\section{REFERENCES}

Almeida, R. A., Patel, D., Friton, G. M. \& Oliver, S. P. (2007). Intracellular killing of mastitis pathogens by penethamate hydriodide following internalization into mammary epithelial cells. $\mathrm{J} \mathrm{Vet}$ Pharmacol Ther 30, 151-156.

Armstrong, L., Jordan, N. \& Millar, A. (1996). Interleukin 10 (IL-10) regulation of tumour necrosis factor alpha (TNF- $\alpha$ ) from human alveolar macrophages and peripheral blood monocytes. Thorax 51, 143-149.

Bannerman, D. D., Paape, M. J., Lee, J. W., Zhao, X., Hope, J. C. \& Rainard, P. (2004). Escherichia coli and Staphylococcus aureus elicit differential innate immune responses following intramammary infection. Clin Diagn Lab Immunol 11, 463-472.

Berry, E. A. \& Hillerton, J. E. (2002). The effect of selective dry cow treatment on new intramammary infections. J Dairy Sci 85, 112-121.

Brouillette, E. \& Malouin, F. (2005). The pathogenesis and control of Staphylococcus aureus-induced mastitis: study models in the mouse. Microbes Infect 7, 560-568.

Brouillette, E., Grondin, G., Lefebvre, C., Talbot, B. G. \& Malouin, F. (2004). Mouse mastitis model of infection for antimicrobial compound efficacy studies against intracellular and extracellular forms of Staphylococcus aureus. Vet Microbiol 101, 253-262.

Cassatella, M. A., Meda, L., Bonora, S., Ceska, M. \& Constantin, G. (1993). Interleukin 10 (IL-10) inhibits the release of proinflammatory cytokines from human polymorphonuclear leukocytes. Evidence for an autocrine role of tumor necrosis factor and IL- $1 \beta$ in mediating the production of IL-8 triggered by lipopolysaccharide. J Exp Med 178, 2207-2211.

Chandler, R. L. (1970). Experimental bacterial mastitis in the mouse. J Med Microbiol 3, 273-282.

Hertting, O., Khalil, A., Jaremko, G., Chromek, M., Li, Y. H., Bakhiet, M., Bartfai, T., Tullus, K. \& Brauner, A. (2003). Enhanced chemokine response in experimental acute Escherichia coli pyelonephritis in IL$1 \beta$-deficient mice. Clin Exp Immunol 131, 225-233.

Hornef, M. W., Wick, M. J., Rhen, M. \& Normark, S. (2002). Bacterial strategies for overcoming host innate and adaptive immune responses. Nat Immunol 3, 1033-1040.
Keefe, G. P. (1997). Streptococcus agalactiae mastitis: a review. Can Vet J 38, 429-437.

Keefe, G. P., Dohoo, I. R. \& Spangler, E. (1997). Herd prevalence and incidence of Streptococcus agalactiae in the dairy industry of Prince Edward Island. J Dairy Sci 80, 464-470.

Kotwal, G. J. (1997). Microorganisms and their interaction with the immune system. J Leukoc Biol 62, 415-429.

Leitner, G., Yadlin, B., Glickman, A., Chaffer, M. \& Saran, A. (2000). Systemic and local immune response of cows to intramammary infection with Staphylococcus aureus. Res Vet Sci 69, 181-184.

Logan, E. F., Mackie, D. P. \& Meneely, D. J. (1984). Immunological features of consecutive intramammary infections with Streptococcus agalactiae in vaccinated and non-vaccinated heifers. Br Vet J 140, 535-542.

Logan, E. F., Mackie, D. P. \& Meneely, D. J. (1986). Distribution of antibody in different immunoglobulin classes in experimental Streptococcus agalactiae infection of the bovine udder. Br Vet J 142, 358-363.

Mackie, D. P. \& Logan, E. F. (1986). Changes in immunoglobulin levels in whey during experimental Streptococcus agalactiae mastitis. Res Vet Sci 40, 183-188.

Maxie, M. G. (editor) (2007). Jubb, Kennedy and Palmer's Pathology of Domestic Animals, 5th edn. Philadelphia: Saunders.

Merl, K., Abdulmawjood, A., Lammler, C. \& Zschock, M. (2003). Determination of epidemiological relationships of Streptococcus agalactiae isolated from bovine mastitis. FEMS Microbiol Lett 226, 87-92.

Nakajima, Y., Mikami, O., Yoshioka, M., Motoi, Y., Ito, T., Ishikawa, Y., Fuse, M., Nakano, K. \& Yasukawa, K. (1997). Elevated levels of tumor necrosis factor-alpha (TNF- $\alpha$ ) and interleukin-6 (IL-6) activities in the sera and milk of cows with naturally occurring coliform mastitis. Res Vet Sci 62, 297-298.

Notebaert, S. \& Meyer, E. (2006). Mouse models to study the pathogenesis and control of bovine mastitis. A review. Vet Q 28, 2-13.

Rambeaud, M., Almeida, R. A., Pighetti, G. M. \& Oliver, S. P. (2003). Dynamics of leukocytes and cytokines during experimentally induced Streptococcus uberis mastitis. Vet Immunol Immunopathol 96, 193-205.

Rubens, C. E., Smith, S., Hulse, M., Chi, E. Y. \& van Belle, G. (1992). Respiratory epithelial cell invasion by group B streptococci. Infect Immun 60, 5157-5163.

Shuster, D. E., Kehrli, M. E., Jr \& Stevens, M. G. (1993). Cytokine production during endotoxin-induced mastitis in lactating dairy cows. Am J Vet Res 54, 80-85.

Soltys, J. \& Quinn, M. T. (1999). Selective recruitment of T-cell subsets to the udder during staphylococcal and streptococcal mastitis: analysis of lymphocyte subsets and adhesion molecule expression. Infect Immun 67, 6293-6302.

Spits, H. \& de Waal Malefyt, R. (1992). Functional characterization of human IL-10. Int Arch Allergy Immunol 99, 8-15.

Tavares, D., Ferreira, P., Vilanova, M., Videira, A. \& Arala-Chaves, M. (1995). Immunoprotection against systemic candidiasis in mice. Int Immunol 7, 785-796.

Wilson, C. D. \& Richards, M. S. (1980). A survey of mastitis in the British dairy herd. Vet Rec 106, 431-435.

Yamanaka, H., Hisaeda, K., Hagiwara, K., Kirisawa, R. \& Iwai, H. (2000). ELISA for bovine interleukin-1 receptor antagonist and its application to mastitic sera and whey. J Vet Med Sci 62, 661-664.

Zhu, Y., Osterlundh, I., Hulten, F. \& Magnusson, U. (2004). Tumor necrosis factor- $\alpha$, interleukin-6, serum amyloid A, haptoglobin, and cortisol concentrations in sows following intramammary inoculation of Escherichia coli. Am J Vet Res 65, 1434-1439. 